\title{
BMJ Open Admission to psychiatric hospital in the early and late postpartum periods: Scottish national linkage study
}

\author{
Julie Langan Martin, ${ }^{1}$ Gary McLean, ${ }^{1}$ Roch Cantwell, ${ }^{2}$ Daniel J Smith ${ }^{1}$
}

To cite: Langan Martin J, McLean G, Cantwell R, et al. Admission to psychiatric hospital in the early and late postpartum periods: Scottish national linkage study. BMJ Open 2016;6:e008758. doi:10.1136/bmjopen-2015008758

- Prepublication history for this paper is available online. To view these files please visit the journal online (http://dx.doi.org/10.1136/ bmjopen-2015-008758)

Received 13 May 2015 Revised 5 August 2015 Accepted 17 September 2015

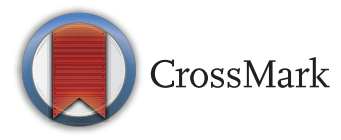

${ }^{1}$ Institute of Health and Wellbeing, University of Glasgow, Mental Health and Wellbeing, Gartnavel Royal Hospital, Glasgow, UK ${ }^{2}$ Perinatal Mental Health Service, Leverndale Hospital, NHS Greater Glasgow and Clyde, Glasgow, UK

Correspondence to Dr Julie Langan Martin; julie.langan@glasgow.ac.uk

\section{ABSTRACT}

Objective: To describe weekly admission rates for affective and non-affective psychosis, major depression and other psychiatric disorders in the early and late postpartum periods. To assess the impact of socioeconomic status, age and parity on admission rates. Methods: Scottish maternity records were linked to psychiatric hospital admissions. 3290 pregnancy-related psychiatric admissions were assessed. Weekly admission rates were calculated for the pregnancy period, early postpartum period (6 weeks after birth) and late postpartum period (up to 2 years after birth), and compared with pre-pregnancy rates (up to 2 years before pregnancy). Admission rates were generated by calculating the total number of admissions for each time period divided by the number of weeks in the period. Incidence rate ratios (IRRs) were generated for each time period, using deprivation, age, parity and record of previous psychiatric hospital care-adjusted Poisson regression models.

Results: Women from more deprived social quintiles accounted for the largest proportion of admissions across all time periods. Compared with pre-pregnancy period, admission rates fell during pregnancy, increased markedly during the early postpartum period, and remained elevated for 2 years after childbirth. Within the most affluent quintile, admission IRRs were higher in the early postpartum period (IRR $=1.29,95 \% \mathrm{Cl} 1.02$ to 1.59 ) than in the late postpartum period (IRR $=0.87,95 \% \mathrm{Cl}$ 0.74 to 0.98 ). For the late postpartum period, there was a positive association between higher maternal age and admission IRRs (ages 20-35 years, IRR $=1.35,95 \% \mathrm{Cl}$ 1.16 to 1.54 and age $>40$ years IRR $=1.72,95 \% \mathrm{Cl} 1.41$ to 2.09).

Conclusions: Rates of psychiatric admission fell during pregnancy and increased in the early postpartum period (particularly during the first 2 weeks after birth), and remained elevated above baseline during the 2-year late postpartum period. An understanding of how social deprivation, age and parity might influence risk of psychiatric admission at different time points could help to target perinatal mental health services more effectively.

\section{INTRODUCTION}

Good maternal mental health is important for normal childhood development. ${ }^{1}$

\section{Strengths and limitations of this study}

Whole of Scotland childbirth and psychiatric admission data used for analyses, rather than local data only.

- Robust measure of socioeconomic status (Scottish Index of Multiple Deprivation) compared with other studies which have used educational status.

- These analyses used only psychiatric admission data, rather than outpatient psychiatric attendances.

- Changes in delivery of perinatal mental health services in different parts of Scotland during the study period may have impacted on admission rates.

However, it is recognised that during pregnancy and the postpartum period, women may experience a diverse range of mental health problems including depression, anxiety and psychosis. ${ }^{2}{ }^{3}$ While the prevalence of postpartum psychosis is relatively low at $1 / 1000$ births, ${ }^{45}$ it is known to be associated with severe adverse outcomes, including maternal suicide and infanticide. ${ }^{6}$ Hospitalisation is often required, due to the severity of psychiatric symptoms and risk of harm to both mother and baby. Postnatal depression, which affects between $10 \%$ and $15 \%$ of mothers ${ }^{78}$ also has important consequences for mother and baby, ${ }^{8}$ and may require hospitalisation if severe. Similarly, anxiety disorders may be associated with adverse outcomes for both the mother and the baby. ${ }^{9}$

Although the risk of postpartum psychosis is recognised as being highest in the first 30 days post partum, ${ }^{10-14}$ there are gaps in our understanding of how sociodemographic factors might influence admission to hospital. ${ }^{11}$ Studies exploring the impact of socioeconomic factors on the development of postpartum psychosis have yielded inconsistent results: some report an association between postpartum psychosis and low 
income,${ }^{15} 16$ whereas others have found no association with social class, ${ }^{17}$ type of employment, ${ }^{18} 19$ or educational level. ${ }^{20}$ Even less is known about the timing of admissions due to major depression, non-affective psychosis and other mental disorders in relation to childbirth, and how sociodemographic factors might influence this.

\section{AIMS OF THE STUDY}

We aimed to assess the risk of psychiatric admission, by International Classification of Diseases (ICD) 10 diagnosis, for the 2 years prechildbirth and postchildbirth for all women who had a delivery in Scotland between 2005 and 2009. We extend previous work by assessing admission rates for the whole Scottish population and in much greater resolution, by assessing periods of 1 week. We focus on psychotic disorders and non-psychotic depression, and specifically assess the impact of socioeconomic status, maternal age and parity on rate and timing of admission.

\section{MATERIALS AND METHODS}

From the Scottish Morbidity Records (SMR) at NHS Scotland's Information Services Division, we linked all maternity records (SMR04), between 2005 and 2009 inclusively, to all psychiatric admissions (SMR02) for the 2-year period immediately preceding and following each maternity record (2003-2011). To determine the effect of childbirth on rate of psychiatric admission, date of psychiatric admission by week in relation to each birth was obtained ( -104 to +104 weeks, where week of childbirth=0). For deliveries in 2005, psychiatric admissions between 2003 and 2007 were captured, and for deliveries in 2009, psychiatric admissions in 2007 until 2011 were captured. For each maternity record, any psychiatric admission was reported by week for the 104 weeks prechildbirth and postchildbirth.

We calculated weekly rates for: (1) all psychiatric admissions, (2) psychosis-only admissions, (3) nonpsychotic depressive episode admissions only and (4) all 'other' admissions (which included alcohol misuse, bipolar disorder, stress-related disorders and personality disorders). Admission types were defined by ICD-10 $\operatorname{codes}^{21}$ : psychosis-only admissions included 'nonaffective psychosis' (F20, F20.3, F20.5, F20.6, F20.8, F20.9, F21X, F22.0, F22.8, F22.9, F23.0, F23.1, F23.2, F23.3, F23.8, F23.9, F24X, F28X, F29X), 'affective psychosis' (F25.0, F25.1, F25.2, F25.9, F30.2, F31.2, F31.5, F32.3, F33.3) and 'postpartum psychosis' (F53.0, F53.1, F53.9); admissions due to a non-psychotic depressive episode included F32.0, F32.00, F32.01, F32.1, F32.10, F32.11, F32.2, F32.8, F32.9, F33.0, F33.00, F33.1, F33.10, F33.11, F33.2, F33.4, F33.8, F33.9. For the category of 'other admissions' we included ICD-10 codes for alcohol misuse (F10.2 and F10.25), bipolar disorder (F31.0, F31.3, F31.30, F31.31, F31.4, F31.6, F31.7, F31.8, and F31.90), stress (F43.0, F43.1, F43.2, F43.20, F43.21, F43.22, F43.23, F43.24, F43.25, and F43.28), and personality disorders (F60.2, F60.3, F60.30, F60.31, F60.9).
Differences in admissions were compared by calculating admission rates within four time periods: from 2 years to the onset of pregnancy (the 'pre-pregnancy period': -104 to -40 weeks); during pregnancy ( -40 to -1 weeks); within 6 weeks of childbirth ('early postpartum': 0 to 6 weeks); and from 7 weeks to 2 years after delivery ('late postpartum': 7 to 104 weeks). Admission rates were generated by calculating the total number of admissions for each time period and dividing by the number of weeks in the period.

There is currently no consensus for defining the postpartum period. Diagnostic and Statistical Manual of Mental Disorders (DSM) V criteria use 4 weeks, ${ }^{22}$ but it is recognised that this has limitations and may be too narrow, especially in relation to diagnosis of depressive episodes. ${ }^{23}$ We chose 6 weeks because it is the obstetric definition of the postpartum period, it is used by WHO to define the postnatal period, ${ }^{24}$ and has been a valid threshold used by other research groups when calculating risk of psychiatric illness after childbirth. ${ }^{13}$

Differences in admission rates for each of the three main admission groups ('psychosis only', 'non-psychotic depression' and 'other') were compared within each of the four time periods. Demographic characteristics of those admitted were also compared for admission type. We divided mothers into six age groups (under 20, 20-25, 2630 , 31-35, 36-40, and 41 years and over) based on recorded age at admission. Socioeconomic status was measured using the Scottish Index of Multiple Deprivation (SIMD) divided into quintiles based on scores at the national average. ${ }^{25}$ Each individual is allocated to an SIMD category based on their postcode, and the index combines information from seven domains which carry different weightings including: current income (28\%), employment $(28 \%)$, health $(14 \%)$, education $(14 \%)$, geographic access to services $(9 \%)$, crime $(5 \%)$ and housing $(2 \%) .^{26}$

We calculated incidence rate ratios (IRRs)from social deprivation, age, parity and record of previous psychiatric hospital care-adjusted Poisson regression models using robust SE variance. ${ }^{27}$ We ran Poisson regression models to allow for covariates to be controlled for and from these models we generated IRRs and 95\% CIs (95\% CI), for admissions within each time period compared to a base rate for deprivation (most deprived quintile), age group (under 20 years), parity (multiparous) and no record of previous psychiatric hospital care. All statistical analyses were performed in STATA V.13.1.

\section{RESULTS}

Complete data were available for 3290 psychiatric admissions during the study period (1889 pregnancies, 1730 women).

\section{Clinical characteristics of admissions in relation to childbirth}

Within the early postpartum period, the most common diagnosis which required hospital admission was 
psychosis $(39.7 \%)$, followed by non-psychotic depression $(22.4 \%)$, and bipolar disorder $(14.4 \%)$ (table 1). Admission with non-psychotic depression was the most common diagnosis for all other time periods. Although admissions for personality disorder accounted for $18.3 \%$ of pre-pregnancy admissions, the proportion of personality disorder admissions during pregnancy and within the extended postpartum period was notably lower $(9.2 \%$ and $12.0 \%$, respectively) (table 1$)$.

\section{Influence of social deprivation, maternal age parity and previous psychiatric care on admission rates}

When compared with the pre-pregnancy period, women admitted during the early postpartum were older (mean age 29.22 vs 26.36 years, $\mathrm{p}<0.001$ ), more likely to have been detained under the Mental Health Act $(17.9 \%$ vs $10.0 \%, \mathrm{p}<0.001)$, had a longer median duration of hospitalisation (17 vs 7 days, $\mathrm{p}<0.001$ ), and less likely to have a history of previous psychiatric care $(56.9 \%$ vs $64.3 \%, \mathrm{p}<0.001$ ) (table 1). Overall, women in more socially deprived quintiles accounted for the largest proportion of admissions (table 1). For example, 25.4\% were from the most deprived quintile compared with $17.1 \%$ from most affluent quintile $(p<0.001)$ (figure 1$)$. This applied within all of the time periods studied, but in the early postpartum period there was a drop in the proportion of women from more deprived quintiles and a rise from more affluent quintiles (figure 1). Women from the most affluent quintile contributed to a greater proportion of early postpartum admissions relative to pre-pregnancy and pregnancy admissions (13\% vs 5.5\% and $7.0 \%$, respectively, $\mathrm{p}<0.001$, figure 1$)$. During $7-104$ weeks after childbirth, patterns of admission in relation to social deprivation were more similar to pre-pregnancy patterns.

Table 2 provides further analysis on the effect of social deprivation, maternal age and parity on admission rates within each of the four admission periods. IRRs tended to vary for all three factors depending on the admission period. Within the early postpartum period, the most affluent quintile had higher admission rates compared to the most deprived quintile, after controlling for age and parity (IRR=1.29, 95\% CI 1.02 to 1.59 ), but lower admission rates within the late postpartum period (IRR $=0.87,95 \%$ CI 0.74 to 0.98$)$. Similarly, older mothers (relative to 'age under 20', controlled for deprivation quintile and parity) had significantly lower admission IRRs in the pre-pregnancy period. This trend was reversed within the late postpartum period, with highest admission IRRs identified for mothers aged over 40 years (IRR=1.72, 95\% CI 1.41 to 2.09) (table 2). Primiparous women (relative to multiparous women controlled for age and deprivation quintile) had lower admission IRRs in the pre-pregnancy period $(\mathrm{IRR}=0.77$, $95 \%$ CI 0.67 to 0.83 ) but higher IRRs within the early postpartum period (IRR $=1.35,95 \%$ CI 1.14 to 1.53 ) (table 2). Women with a history of previous psychiatric admission had higher admission IRRs in the pre-pregnancy period (IRR $1.23,95 \%$ CI 1.10 to 1.38 ) and pregnancy period (IRR 1.28, 95\% CI 103 to 1.60), but lower admission IRRs in the late postpartum period (IRR $0.91,95 \%$ CI 0.86 to 0.97 ). No significant difference in admission IRRs was found for the postpartum period.

\section{Weekly admission rates in relation to childbirth}

Figures 2 and $3 \mathrm{~A}-\mathrm{C}$ illustrate the relationship between weekly psychiatric admission rates and childbirth for the 2 years before and after childbirth. Figure 2 is for all admissions combined, figure 3A for 'psychosis only' admissions, figure 3B for 'non-psychotic depression' admissions, and figure 3C for the group of 'other admissions'. The mean weekly admission rate for all groups combined (figure 2) fell from the onset of pregnancy (from 13.3 to 7.9 admissions per week during pregnancy) then increased substantially during the early postpartum period (to 46.2 admissions per week), with a peak of 59 admissions during the second week after delivery. In the late postpartum period, the mean weekly admission rate was higher than for pre-pregnancy levels (18.8 vs 13.3 admissions per week).Psychosis admission rates fell from the onset of pregnancy (from 2.7 to 1.7 admissions per week during pregnancy) then peaked at 29 admissions during the second week after delivery (figure 3A). Non-psychotic depression admissions fell slightly during pregnancy (to 2.03 per week compared with 2.92 admissions per week pre-pregnancy), and rose during the postpartum period, particularly for the first week after delivery (13 admissions) (figure 3B). For 'other admissions', the weekly rate of admission also fell during pregnancy (4.3 per week compared to a pre-pregnancy rate of 8.3), and were highest within the first week after delivery (20 admissions per week) (figure 3C).

\section{DISCUSSION}

Overall, we found that the early postpartum period, as well as an extended postpartum period (up to 2 years after delivery), were periods of elevated risk of admission to psychiatric hospital for women. The much higher risk in the early postpartum period is consistent with previous work. ${ }^{4}{ }^{10}$ We also identified that risk of admission (particularly admission for psychosis) peaked during the second week after childbirth, and admission rates for non-psychotic depression were highest during the first week after childbirth. Elevated late postpartum rates of admission were evident over a range of psychiatric diagnoses.

The primary focus of this study was to assess the impact of social deprivation, maternal age and parity on rates and type of admission during three time periods (pregnancy, early postpartum and late postpartum), in comparison with pre-pregnancy rates. A number of notable findings emerged. Although women from more deprived social quintiles represented the largest 
Table 1 Sociodemographic characteristics for all psychiatric admissions, by study time periods

\begin{tabular}{|c|c|c|c|c|}
\hline & $\begin{array}{l}\text { Pre-pregnancy } \\
\text { admissions }\end{array}$ & $\begin{array}{l}\text { Pregnancy } \\
\text { admissions }\end{array}$ & $\begin{array}{l}\text { Early postpartum } \\
\text { admissions }\end{array}$ & $\begin{array}{l}\text { Late postpartum } \\
\text { admissions }\end{array}$ \\
\hline Number of admissions $\mathrm{n},(\%)$ & $853(25.9)$ & $315(9.8)$ & $277(8.5)$ & 1845 (57.2) \\
\hline Weekly admission rate & 13.3 & 7.9 & 46.2 & 18.8 \\
\hline Mean age (SD) & $26.4(6.2)$ & $28.3(6.3)$ & $29.2(6.8)$ & $28.5(6.2)$ \\
\hline $\begin{array}{l}\text { Median duration of } \\
\text { admission, days (IQR) }\end{array}$ & $7(14)$ & $9(18)$ & $17(29)$ & $8(19)$ \\
\hline $\begin{array}{l}\text { Detained under Mental } \\
\text { Health Act, } n(\%)\end{array}$ & $85(10.0)$ & $41(13.0)$ & $49(17.9)$ & $184(10.0)$ \\
\hline \multicolumn{5}{|l|}{ Diagnoses, n (\%) } \\
\hline Psychosis & $134(15.7)$ & $61(19.4)$ & $110(39.7)$ & $346(18.8)$ \\
\hline Non-psychotic depression & $187(21.9)$ & $81(25.7)$ & $62(22.4)$ & $531(28.8)$ \\
\hline \multicolumn{5}{|l|}{ Other } \\
\hline Bipolar disorder & $57(6.7)$ & $30(9.5)$ & $40(14.4)$ & $153(8.3)$ \\
\hline Alcohol misuse & $63(7.4)$ & $14(4.4)$ & $4(1.4)$ & $119(6.4)$ \\
\hline Stress related & $74(8.7)$ & $31(9.8)$ & $20(7.2)$ & $174(9.4)$ \\
\hline Personality disorders & $156(18.3)$ & $29(9.2)$ & $8(2.9)$ & $222(12.0)$ \\
\hline Miscellaneous & $182(21.3)$ & $69(21.9)$ & $33(11.9)$ & $300(16.3)$ \\
\hline \multicolumn{5}{|l|}{ SIMD quintile $n,(\%)$} \\
\hline 1: Most deprived & $390(45.7)$ & $156(49.5)$ & $98(35.3)$ & $788(42.7)$ \\
\hline 2 & $200(23.4)$ & 73 (23.2) & $49(17.7)$ & 441 (23.9) \\
\hline 3 & $146(17.1)$ & $38(12.1)$ & $58(21.0)$ & $271(14.7)$ \\
\hline 4 & $70(8.2)$ & $26(8.3)$ & $36(13.0)$ & 239 (13.0) \\
\hline 5: Most affluent & $47(5.5)$ & $22(7.0)$ & $36(13.0)$ & $106(5.7)$ \\
\hline \multicolumn{5}{|l|}{ Age group n, (\%) } \\
\hline Under 20 & $109(12.8)$ & $29(9.2)$ & $22(8.0)$ & $114(6.2)$ \\
\hline $20-25$ & $320(37.5)$ & $88(27.9)$ & $86(31.2)$ & $520(28.2)$ \\
\hline $26-30$ & $194(22.7)$ & $88(27.9)$ & 78 (28.3) & $546(29.6)$ \\
\hline $30-34$ & 159 (18.6) & $57(18.1)$ & $57(20.5)$ & $384(20.8)$ \\
\hline $35-39$ & $61(7.1)$ & $44(14.1)$ & $28(10.2)$ & $214(11.6)$ \\
\hline 40 and over & $10(1.2)$ & $9(2.8)$ & $5(1.9)$ & $63(3.4)$ \\
\hline \multicolumn{5}{|l|}{ Parity $n,(\%)$} \\
\hline No previous pregnancy & $574(67.3)$ & $215(68.2)$ & $162(58.6)$ & $1207(65.4)$ \\
\hline Previous pregnancy & 287 (33.3) & $100(31.8)$ & $115(41.4)$ & $638(34.6)$ \\
\hline \multicolumn{5}{|l|}{ Previous inpatient care $n,(\%)$} \\
\hline Yes & $548(64.3)$ & $210(66.7)$ & $158(56.9)$ & $1096(59.4)$ \\
\hline No & 305 (35.7) & 105 (33.3) & $119(43.1)$ & 749 (40.6) \\
\hline
\end{tabular}

proportion of admissions overall, during the early postpartum period, the relative proportion of women from more affluent quintiles increased, and the relative proportion from more deprived quintiles fell (figure 1). After controlling for age group and parity, the IRR during the early postpartum period was significantly

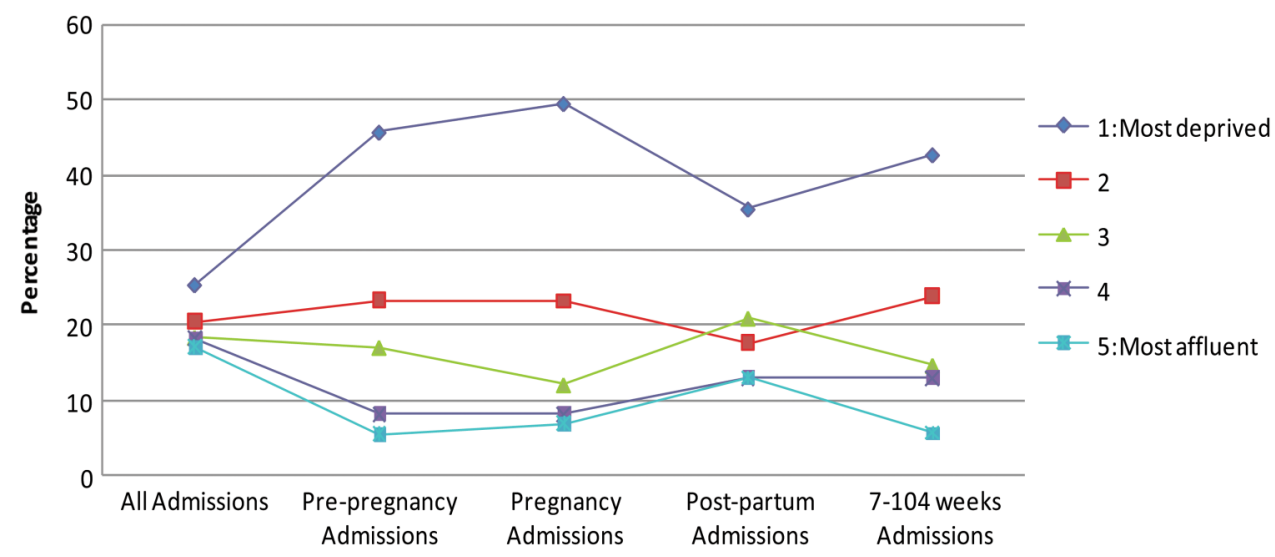

Figure 1 Social deprivation status of pregnancy-related admissions, by time period. 
Table 2 Incidence rate ratios (IRRs) for admissions during different time periods, by social deprivation, maternal age, parity and previous psychiatric admission

\begin{tabular}{|c|c|c|c|c|}
\hline & $\begin{array}{l}\text { Pre-pregnancy } \\
\text { admissions } \\
\mathrm{N}=853\end{array}$ & $\begin{array}{l}\text { Pregnancy } \\
\text { admissions } \\
\mathrm{N}=315\end{array}$ & $\begin{array}{l}\text { Early postpartum } \\
\text { admissions } \\
\mathrm{N}=277\end{array}$ & $\begin{array}{l}\text { Late postpartum } \\
\text { admissions } \\
\mathrm{N}=1845\end{array}$ \\
\hline & IRR (95\%CI) & IRR (95\%CI) & IRR (95\%CI) & IRR (95\%CI) \\
\hline \multicolumn{5}{|c|}{ Deprivation quintile } \\
\hline Most deprived & 1 & 1 & 1 & 1 \\
\hline 2 & $1.00(0.87$ to 1.15$)$ & $0.88(0.67$ to 1.14$)$ & $1.04(0.84$ to 1.26$)$ & $1.03(0.95$ to 1.10$)$ \\
\hline 3 & $1.06(0.91$ to 1.23$)$ & $0.67(0.47$ to 0.93$)$ & $1.04(0.83$ to 1.21$)$ & $0.92(0.83$ to 1.01$)$ \\
\hline 4 & 0.75 (0.61 to 0.91$)$ & $0.63(0.41$ to 0.93$)$ & $1.18(0.92$ to 1.51$)$ & $1.13(0.97$ to 1.22$)$ \\
\hline Least deprived & 0.90 (0.69 to 1.15$)$ & 0.94 (0.61 to 1.45$)$ & 1.29 (1.02 to 1.59$)$ & 0.87 (0.74 to 0.98$)$ \\
\hline \multicolumn{5}{|l|}{ Age group (years) } \\
\hline Under 20 & 1 & 1 & 1 & 1 \\
\hline 20-35 & 0.82 (0.69 to 0.97$)$ & $0.83(0.55$ to 1.22$)$ & $1.21(0.89$ to 1.63$)$ & 1.35 (1.16 to 1.54$)$ \\
\hline $26-30$ & 0.52 (0.42 to 0.62$)$ & $0.90(0.60$ to 1.34$)$ & 1.19 (0.86 to 1.62$)$ & 1.51 (1.30 to 1.75$)$ \\
\hline $31-35$ & 0.55 (0.44 to 0.66$)$ & $0.80(0.52$ to 1.22$)$ & $1.10(0.79$ to 1.53$)$ & 1.42 (1.21 to 1.65$)$ \\
\hline $36-40$ & 0.38 (0.29 to 0.49$)$ & $1.10(0.69$ to 1.72$)$ & $1.05(0.72$ to 1.53$)$ & 1.45 (1.23 to 1.71$)$ \\
\hline Over 40 & 0.24 (0.12 to 0.43$)$ & $0.59(0.25$ to 1.39$)$ & $0.77(0.46$ to 1.53$)$ & 1.72 (1.41 to 2.09$)$ \\
\hline \multicolumn{5}{|l|}{ Parity } \\
\hline Primiparous & $0.77(0.67$ to 0.83$)$ & $0.90(0.71$ to 1.14$)$ & 1.35 (1.14 to 1.53$)$ & $1.07(1.01$ to 1.14$)$ \\
\hline \multicolumn{5}{|c|}{ Previous inpatient care } \\
\hline Yes & $1.23(1.10$ to 1.38$)$ & $1.28(1.03$ to 1.60$)$ & $0.86(0.73$ to 1.01$)$ & 0.91 (0.86 to 0.97$)$ \\
\hline
\end{tabular}

higher for women from the most affluent quintile compared with those from the most deprived quintile (table 2). As the majority of admissions in this time period were due to psychosis, this finding may suggest that higher socioeconomic status might be a risk factor for postpartum psychosis. This is somewhat unexpected, because in the female population, generally low socioeconomic status is associated with increased risk of psychosis. ${ }^{28}$ However, historical accounts may be informative in this regard: as early as 1859 , Gundry noted that for postpartum psychosis 'all classes seem equally liable', ${ }^{29}$ and in 1838, Esquirol reported that postpartum psychosis was equally common among wealthy women and poorer women. ${ }^{30}$ There are also anecdotal and

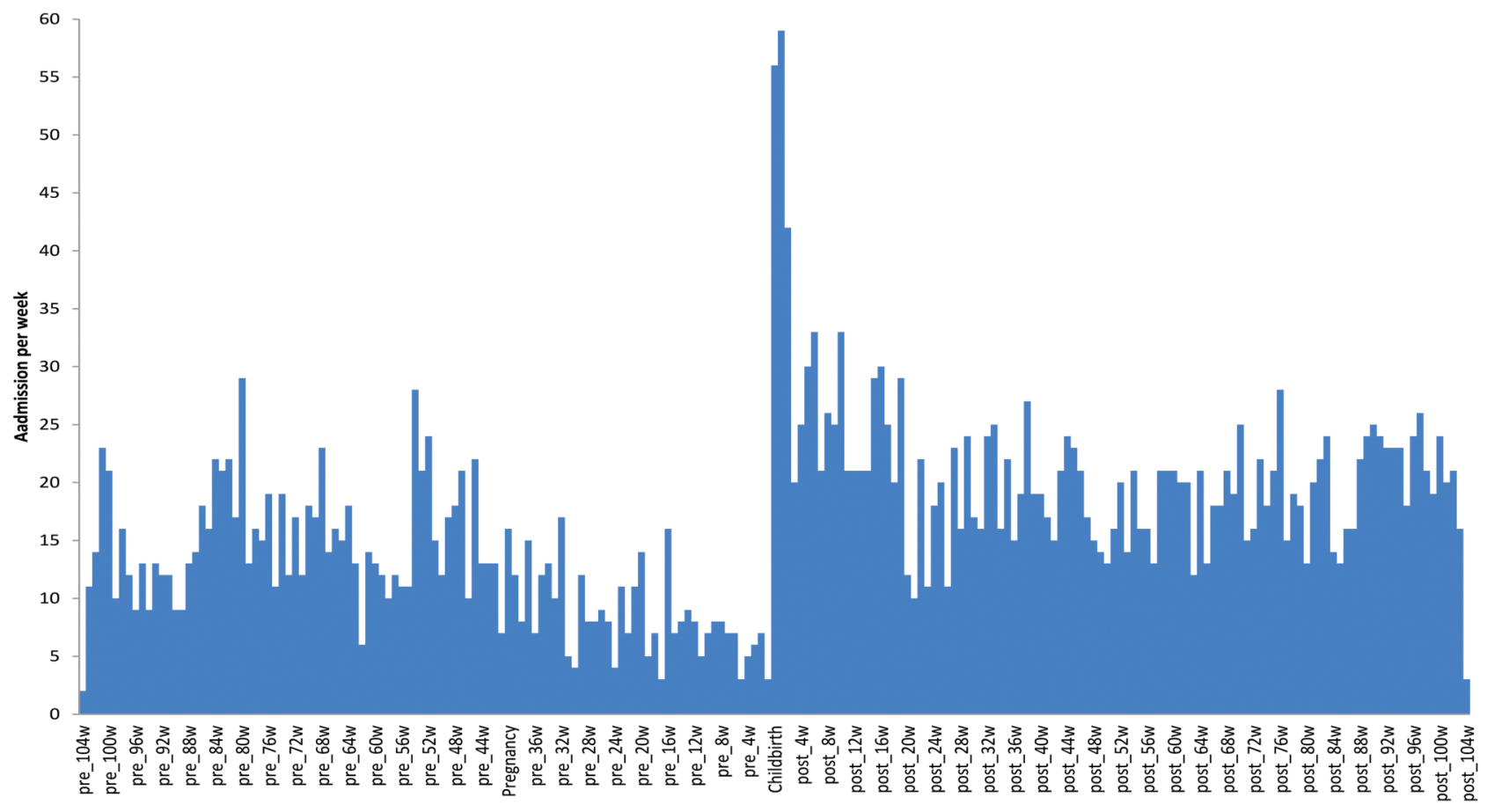

Figure 2 Admissions per week in relation to childbirth (all diagnoses). 


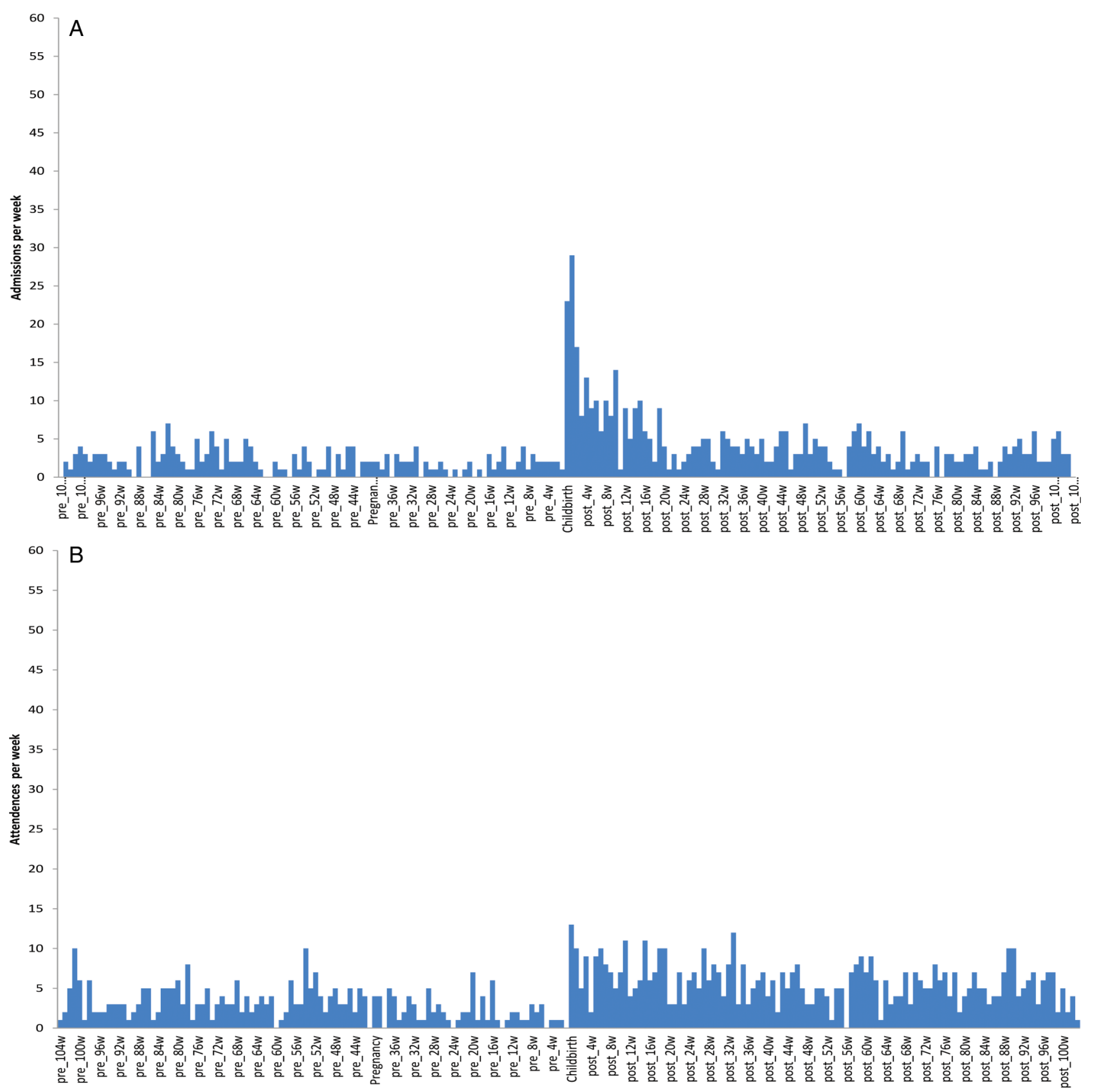

Figure 3 (A) Admissions per week in relation to childbirth (psychosis). (B) Admissions per week in relation to childbirth (non-psychotic depression). (C) Admissions per week in relation to childbirth (other admissions).

clinical reports of more highly educated women from more affluent backgrounds being at particularly elevated risk of postpartum psychosis, but a clear and consistent association between socioeconomic status, education and risk of postpartum psychosis has not yet been reported in the modern literature. ${ }^{17} 19$ Our findings, which have been controlled for parity and age, add to current knowledge in this field.

We also found that admissions during the postpartum period were elevated in primiparous women (relative to multiparous) after controlling for social deprivation and age. This is consistent with other studies. ${ }^{10}{ }^{14}$ Although reasonably well established, this association is poorly understood. The avoidance of subsequent pregnancies has been discounted as one explanatory factor ${ }^{14} 3132$ but other possible explanations relate to psychosocial stress associated with first-time motherhood and possible biological differences between a first and subsequent pregnancy. Preeclampsia has a strong association with primiparity, but its risk in subsequent pregnancies has been relatively well defined, with a change in partner and increasing time between pregnancies ${ }^{33} 34$ recognised as risk factors. It is thought that this may suggest an immunological basis for preeclampsia. ${ }^{35}$ Given that increasing time between pregnancies is also associated with risk of postpartum psychosis, ${ }^{36}{ }^{37}$ further work on 


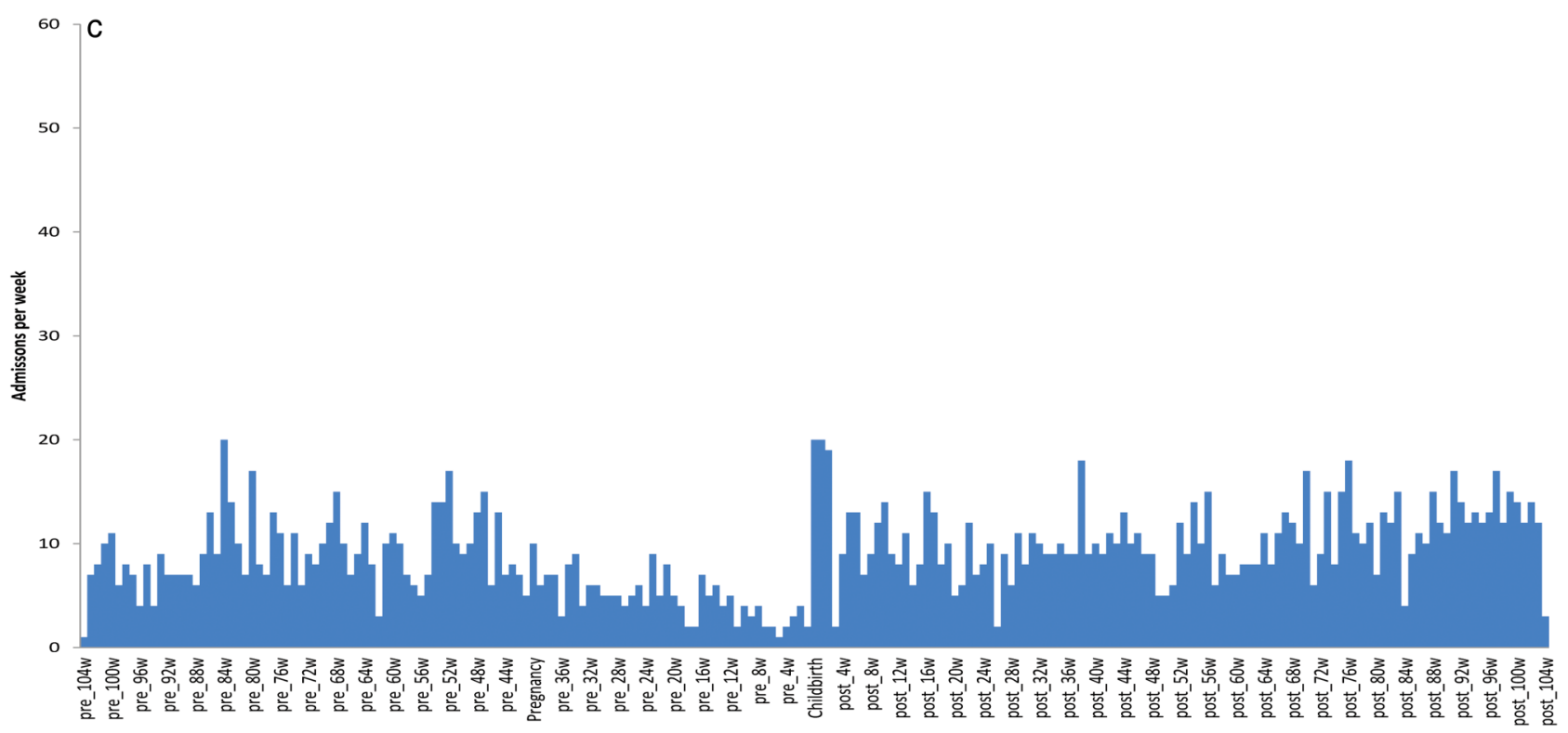

Figure 3 Continued

the relationship between parity and postpartum psychosis is warranted.

For age group, we found that the association between maternal age and psychiatric admission was inconsistent across the time periods studied. Older mothers (relative to the youngest age group) were at lower risk of admission in the pre-pregnancy period but at higher risk of admission in the late postpartum period, even after controlling for social deprivation and parity. This finding is of note both because the mean age of mothers is rising in Scotland, ${ }^{38}$ and because of the current focus of health services on the immediate postpartum period. ${ }^{39}$

No significant differences in admission rates by age were found for the early postpartum period. This is similar to the finding by Kendell and colleagues ${ }^{10}$ and Munk Olsen and colleagues, ${ }^{11}$ but differs from work undertaken by others some of whom have identified an increased rate of admission due to psychotic disorder in older women ${ }^{20} 36$ and others ${ }^{15}$ who have reported an association between younger age and postpartum admissions. Clearly, further study in this area is merited.

The finding that women with a history of previous psychiatric admission had higher admission IRRs in the prepregnancy and pregnancy periods, lower admission IRRs in the late postpartum period, and no significant difference in admission IRRs in the postpartum period is of interest. The number of psychiatric admissions is known to be a powerful predictor of readmission ${ }^{40}$ in the general psychiatric population, and so, further investigation into its importance in admission rates in the early and late postnatal period may be warranted.

\section{Strengths and limitations}

Strengths of this study include the completeness of the sample, which was obtained from record linkage for the whole of Scotland. Recording of ICD-10 diagnosis on the psychiatric admission record allowed detailed analyses of rates and patterns of admission by diagnosis. Linkage to birth records allowed the incidence rate of admission to be calculated on a weekly basis, with greater resolution for patterns of admission in relation to childbirth. The use of the SIMD score as a marker of social deprivation is a further strength of our study. This is recognised as a robust and reproducible marker of deprivation in Scotland, and as such may be a more useful measure of deprivation than previously used measures such as educational attainment. ${ }^{17}$

However, some limitations in this work are acknowledged. First, only psychiatric admission data were used, with no use of outpatient data. Although most women with a psychotic illness in the early postpartum period will be admitted to hospital, this will not be true for other non-psychotic illnesses and for psychotic illnesses occurring out with the immediate postpartum period. This may have affected our calculated relative rates of admission. The variation in development of crisis teams, intensive home treatment teams, and the variation in access to Mother and Baby Units across Scotland over the study period may also have impacted on rates of hospitalisation. Although we were able to determine if individuals had had a previous psychiatric admission, the number of previous admissions was not available. Unfortunately, we were not able to adjust for these factors. Multiple comparisons between multiple groups can increase the risk of a type I error, however, we attempted to reduce the likelihood of this by using appropriate statistical techniques, and conservatively attributing significance at $\mathrm{p}<0.001$.

In conclusion, this study highlights that the first 2 years following childbirth are associated with an increased risk of psychiatric admission, with a particularly elevated risk in the early postpartum period, for both psychosis and 
non-psychotic depression. Risk of admission due to psychosis was highest in the second week following childbirth, and risk of admission for non-psychotic depression was highest within the first week of childbirth. Although most admissions, overall, were for women from more deprived quintiles, women from the most affluent quintiles were at elevated relative risk of admission during the early postpartum period. Primiparity was a risk factor for postpartum admission even after accounting for age and social deprivation, and risk of admission was associated with older maternal age in the late postpartum period. In addition, we found that early postpartum admissions were characterised by longer duration of admission and greater use of Mental Health Act detention, likely reflecting the severity of illnesses occurring at this time.

The UK Confidential Enquiry into Maternal Deaths highlights the very significant risks associated with maternal mental illness, and points to opportunities for the prediction and prevention of adverse clinical outcomes. ${ }^{41}$ This study provides a more detailed understanding of the patterns of admission, type of admission and sociodemographic factors associated with admission in the first 2 years following childbirth. This adds to our knowledge of risk, and may help target future resources more effectively.

Acknowledgements The authors are very grateful to ISD Scotland for their assistance.

Contributors JLM wrote the initial draft of the paper and was involved in design of the study. GM was involved in data anaylses and drafting the paper $\mathrm{RC}$ and DJS were involved in the study design and drafting of the paper.

Funding This work was funded by NHS Greater Glasgow \& Clyde project code: GN12CP246.

\section{Competing interests None declared.}

Ethics approval NHS Privacy Advisory Committee (PAC) (XRB12089).

Provenance and peer review Not commissioned; externally peer reviewed.

Data sharing statement Data included in the study are available to the four authors only.

Open Access This is an Open Access article distributed in accordance with the Creative Commons Attribution Non Commercial (CC BY-NC 4.0) license, which permits others to distribute, remix, adapt, build upon this work noncommercially, and license their derivative works on different terms, provided the original work is properly cited and the use is non-commercial. See: http:// creativecommons.org/licenses/by-nc/4.0/

\section{REFERENCES}

1. Horowitz SM, Briggs-Gowan MJ, Storfer-Isser A, et al. Persistence of Maternal Depressive Symptoms throughout the early years of childhood. J Womens Health 2009;18:637-45.

2. Priest SR, Austin MP, Barnett BB, et al. A psychosocial risk assessment model (PRAM) for use with pregnant and postpartum women in primary care settings. Arch Womens Ment Health 2008:11:307-17.

3. Kingston D, Heaman M, Fell D, et al. Factors associated with perceived stress and stressful life events in pregnant women: findings from the Canadian Maternity Experiences Survey. Matern Child Health J 2012;16:158-68.

4. Terp IM, Mortensen PB. Post-partum psychoses. Clinical diagnoses and relative risk of admission after parturition. $\mathrm{Br} J$ Psychiatry 1998;172:521-6.

5. Halbreich U. Postpartum disorders: multiple interacting underlying mechanisms and risk factors. J Affect Disord 2005;88:1-7.
6. Wisner KL, Peindl K, Hanusa BH. Symptomatology of affective and psychotic illnesses related to childbearing. J Affect Disord 1994;30:77-87.

7. O'Hara MW, Swain AM. Rates and risk of postpartum depression: a meta-analysis. Int Rev Psychiatry 1996;8:37-54.

8. Seyfried LS, Marcus SM. Postpartum mood disorders. Int Rev Psychiatry 2003;15:231-42.

9. Martini J, Petzoldt J, Einsle F, et al. Risk factors and course patterns of anxiety and depressive disorders during pregnancy and after delivery: a prospective-longitudinal study. J Affect Disord 2015;175:385-95

10. Kendell RE, Chalmers JC, Platz C. Epidemiology of puerperal psychoses. Br J Psychiatry 1987;150:662-73.

11. Munk-Olsen T, Laursen TM, Pedersen CB, et al. New parents and mental disorders: a population-based register study. JAMA 2006;296:2582-9.

12. Jones I, Craddock N. Bipolar disorder and childbirth: the importance of recognising risk. Br J Psychiatry 2005;186:453-4.

13. Di Florio A, Forty L, Gordon-Smith K, et al. Perinatal episodes across the Mood Disorder Spectrum. JAMA Psychiatry 2013;70:168-75.

14. Brockington IF. Motherhood and mental health. Oxford: Oxford University Press, 1998.

15. Upadhyaya SK, Sharma A, Raval CM. Postpartum psychosis: risk factors identification. N Am J Med Sci 2014;6:274-7.

16. Nager A, Johansson LM, Sundquist K. Neighbourhood socioeconomic environment and risk of postpartum psychosis. Arch Womens Ment Health 2006;9:81-6.

17. McNeil TF. A prospective study of postpartum psychoses in a high-risk group. Relationships to demographic and psychiatric history characteristics. Acta Psychiatr Scand 1987;75:35-43.

18. Bågedahl-Strindlund $M$. Parapartum mental illness: timing of illness onset and its relation to symptoms and socio-demographic characteristics. Acta Psychiatr Scand 1986;74:490-6.

19. Kumar R, Marks M, Platz C, et al. Clinical survey of a psychiatric mother and baby unit: characteristics of 100 consecutive admissions. J Affect Disord 1995;33:11-22.

20. Nager A, Johansson LM, Sundquist K. Are socio-demographic factors and year of delivery associated with hospital admission for postpartum psychosis? A study of 500,000 first-time mothers. Acta Psychiatr Scand 2005;112:47-53.

21. ICD 10 Codes 2010. http://apps.who.int/classifications/icd10/browse/ 2010/en

22. American Psychiatric Association. Diagnostic and statistical manual of mental disorders. 5th edn. text revision. Washington DC: American Psychiatric Association, 2013.

23. Munk-Olsen T, Laursen TM, Mendelson T, et al. Risks and predictors of readmission for a mental disorder during the postpartum period. Arch Gen Psychiatry 2009;66:189-95.

24. Chapter 4 Post Natal Care C Warren, P Daly, L Toure, P Mongi. http://www.who.int/pmnch/media/publications/aonsectionlll_4.pdf

25. http://simd.scotland.gov.uk/publication-2012/ introduction-to-simd-2012/overview-of-the-simd/what-is-the-simd/

26. SIMD Scotland. http://simd.scotland.gov.uk/publication-2012/ introduction-to-simd-2012/overview-of-the-simd/what-is-the-simd/

27. Carter RE, Lipsitz SR, Tilley BC Quasi-likelihood estimation for relative risk regression models. Biostatistics 2005;6:39-44.

28. Sundquist $K$, Frank $G$, Sundquist J. Urbanisation and incidence of psychosis and depression: follow-up study of 4.4 million women and men in Sweden. Br J Psychiatry 2004;184:293-8.

29. Gundry R. Observations on puerperal insanity. Am J Insanity 1859:16:294-320

30. Esquirol JED. Mental maladies: a treatise on insanity. Facsimile of English edition of 1845. New York: Hafner, 1965.

31. Blackmore ER, Jones I, Doshi M, et al. Obstetric variables associated with bipolar affective puerperal psychosis. $\mathrm{Br} J$ Psychiatry 2006:188:32-6.

32. Di Florio A, Jones L, Forty L, et al. Mood disorders and parity-a clue to the aetiology of the postpartum trigger. $J$ Affect Disord 2014;152-154:334-9.

33. Steegers EA, von Dadelszen P, Duvekot JJ, et al. Preeclampsia. Lancet 2010;376:631-44.

34. Basso O, Christensen $\mathrm{K}$, Olsen J. Higher risk of preeclampsia after change of partner. An effect of longer interpregnancy intervals? Epidemiology 2001:12:624-9.

35. Robillard PY, Dekker G, Chaouat G, et al. Epidemiological studies on primipaternity and immunology in preeclampsia-a statement after twelve years of workshops. J Reprod Immunol 2011;89:104-17. 
36. Paffenbarger RS Jr. Epidemiological aspects of parapartum mental illness. Br J PrevSoc Med 1964;18:189-95.

37. Munk-Olsen T, Jones I, Laursen TM. Birth order and postpartum psychiatric disorders. Bipolar Disord 2014;16:300-7.

38. http://www.oecd.org/els/soc/SF2.3\%20Mean\%20age\%20of\%20mother \%20at\%20first\%20childbirth\%20-\%20updated\%20240212.pdf

39. http://www.gro-scotland.gov.uk/press/news2012/rgs-annual-reviewpublished.html
40. SPARRA Mental Health: Scottish Patients at Risk of Readmission and Admission (to psychiatric hospitals or units) A report on the development of SPARRA MH and recommendations for its use. http:// www.isdscotland.org/Health-Topics/.../SPARRA-MH-report-final.doc

41. Cantwell R, Clutton-Brock T, Cooper G, et al. Saving mothers' lives: reviewing maternal deaths to make motherhood safer: 2006-2008. The Eighth Report of the Confidential Enquiries into Maternal Deaths in the United Kingdom. BJOG 2011;118(Suppl 1):1-203. 